\title{
Dispositivo intrauterino migrado a la cavidad abdominal con embarazo intrauterino no evolutivo: reporte de caso
}

\author{
Coral Bravo A. ${ }^{1}$, Cristina Sánchez R. ${ }^{1}$, María del Puerto García A. ${ }^{1}$, Ana Pomares P. ${ }^{1}$, \\ Julio Segarra R.' \\ ${ }^{1}$ Servicio de Obstetricia y Ginecología. Hospital Central de la Defensa Gómez Ulla, Madrid, España.
}

\section{RESUMEN}

La migración de un dispositivo intrauterino a la cavidad abdominal es una complicación poco frecuente de este eficaz método contraceptivo, sin embargo debe sospecharse ante la imposibilidad de visualizar los hilos del dispositivo vía vaginal y la ausencia intrauterina del mismo por ecografía. Si bien la migración abdominal puede ser asintomática, algunos casos pueden producir clínica de severidad variable incluyendo dolor abdominal y complicaciones derivadas de la formación de adherencias o la perforación de vísceras pélvicas y abdominales. Su detección intraabdominal debe sospecharse en primer lugar por ecografía y confirmarse mediante radiología simple de abdomen. Una vez localizado el dispositivo migrado, se recomienda su extracción inmediata, incluso en casos asintomáticos, con el fin de evitar las complicaciones derivadas de su desplazamiento. La laparoscopia será de primera elección en estos casos para la extracción. Presentamos un caso de migración intraabdominal de dispositivo intrauterino concurrente a un embarazo intrauterino no evolutivo.

\section{PALABRAS CLAVE: Dispositivo intrauterino, perforación uterina, migración de dispositivo intrauterino, laparoscopia}

\section{SUMMARY}

Migration of an intrauterine device to the abdominal cavity is a rare complication of this effective contraceptive method, however, it must be suspected upon the inability to visualize the wires vaginally and the absence of intrauterine device by ultrasound. While its abdominal migration can be asymptomatic, some cases may produce variable clinical severity including abdominal pain and complications resulting from the formation of adhesions or perforation of pelvic and abdominal viscera. Its intraabdominal detection should be suspected first by ultrasound and confirmed by plain abdominal X-ray. Once the migrated device is located, immediate removal is recommended, even in asymptomatic cases, in order to avoid complications arising from its displacement. Laparoscopy will be the first choice in these cases for extraction. We report a case of intraabdominal migration of intrauterine device concurrent with a non-evolutive intrauterine pregnancy.

KEY WORDS: Intrauterine device, uterine perforation, intrauterine device migration, laparoscopy 


\section{INTRODUCCIÓN}

El dispositivo intrauterino (DIU) representa uno de los métodos anticonceptivos de uso más común en todo el mundo, con altas tasas de eficacia contraceptiva situadas entre 98-99\% (1).

A pesar de su eficacia, su uso no está exento de complicaciones. Las más frecuentes están relacionadas con su malposición, como son la expulsión del dispositivo, el desplazamiento y la perforación uterina. Se estima que hasta un $10 \%$ de los DIUs pueden expulsarse vía vaginal especialmente en mujeres que padecen menorragias o en periodo posparto (1). El desplazamiento ocurre hasta en un $25 \%$ de las ocasiones y se relaciona fundamentalmente con las menorragias y las anomalías morfológicas uterinas (2). La complicación más severa durante su inserción es la perforación uterina, que se estima ocurre en 1-13/1000 procedimientos (3). Esa complicación puede pasar inadvertida y ser asintomática o bien cursar con síntomas agudos posprocedimiento o a largo plazo. En los casos inadvertidos existe la posibilidad de migración del dispositivo a otras localizaciones intrabdominales o pélvicas en las que puede cursar con complicaciones de severidad variable (4). La malposición del DIU a su vez limita su eficacia contraceptiva pudiendo dar lugar a embarazos no deseados.

El diagnóstico certero y precoz de la migración del DIU es necesario para minimizar las complicaciones, proporcionar un tratamiento mínimamente invasivo y evitar gestaciones no deseadas.

Presentamos un caso de extracción laparoscópica de un DIU localizado en la cavidad abdominal, concurrente con un embarazo intrauterino no evolutivo.

\section{Caso clínico}

Mujer de 34 años atendida en urgencias por dolor abdominal en el contexto de un test de embarazo positivo. En su historia obstétrica destacaban 6 gestaciones con resultado de 3 partos y 3 abortos. Refería ser portadora de un DIU con cobre (T-380A) desde hacía un año cuya inserción transcurrió sin incidencias y presentaba en el momento de su ingreso una amenorrea de 8 semanas.

La exploración física reveló un útero aumentado de tamaño concordante con la amenorrea, escaso sangrado vaginal, imposibilidad de visualizar los guías del DIU y dolor hipogástrico a la palpación, sin signos de irritación peritoneal. La exploración ecográfica mostraba un saco gestacional intrauterino bien implantado de $20 \mathrm{~mm}$, sin estructuras embrionarias. Los ovarios presentaban ecoestructura normal, sin embargo, en la región anexial izquierda se observaba una estructura lineal hiperrefringente que sugería la presencia de un DIU intraabdominal desplazado de su posición normal (Figura 1A). Una placa simple de abdomen confirmó los hallazgos (Figura 1B).

Ante los hallazgos clínicos y radiológicos la paciente ingresa con el diagnóstico de gestación anembrionada y DIU migrado a cavidad abdominal. Durante el ingreso se realiza un legrado obstétrico evacuador sobre la gestación no evolutiva y una laparoscopia con el fin de retirar el DIU. Durante el procedimiento quirúrgico se visualizan con facilidad los hilos del DIU y el propio dispositivo englobados en el espesor de un tejido adherencial comprendido entre el ligamento ancho izquierdo, la trompa izquierda y el recto-sigma, por lo que se procede a su extracción (Figura 2), evolucionando la paciente favorablemente tras la intervención.

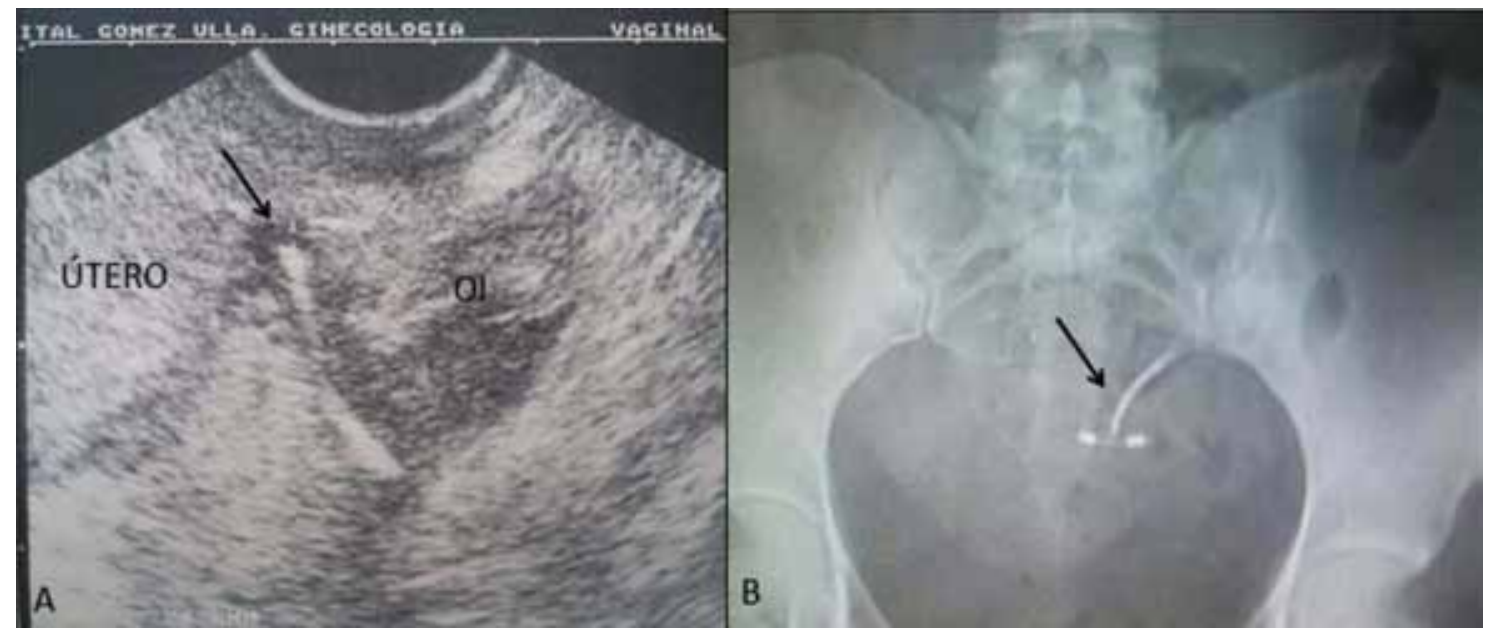

Figura 1. Imágenes ecográfica $(A)$ y por radiografía simple abdominal $(B)$ de la localización extrauterina del DIU (flecha) en la cavidad abdominal. (OI: ovario izquierdo). 


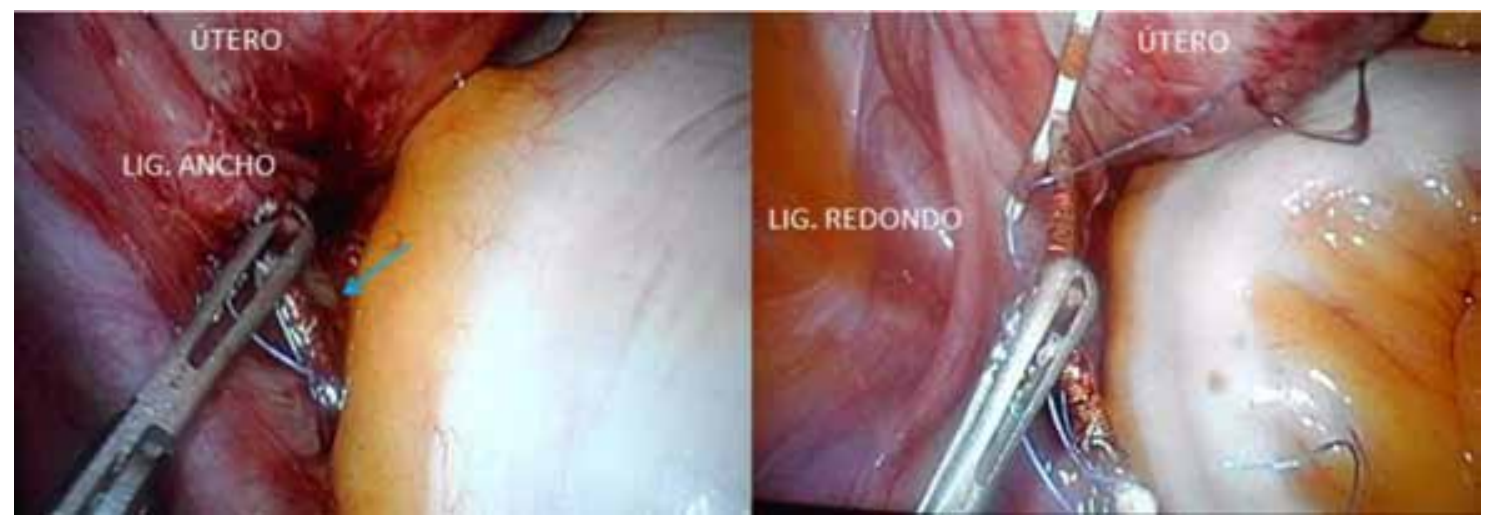

Figura 2. Imágenes intraoperatorias de la extracción laparoscópica del DIU. A) localización de los hilos y vástago del DIU en un repliegue formado por adherencias entre el ligamento ancho izquierdo y el rectosigma. B) Extracción completa del DIU mediante pinzas de agarre.

El resultado del estudio histológico de los restos abortivos confirmó la ausencia de embrión en los mismos y la presencia de estructuras vellositarias de aspecto normal.

\section{DISCUSIÓN}

Presentamos el caso clínico de una paciente diagnosticada de migración de DIU a la cavidad abdominal concurrente con un embarazo intrauterino, a la que se practica cirugía laparoscópica para la remoción del dispositivo.

El desplazamiento de un DIU desde su posición intrauterina a una localización extrauterina en la cavidad abdominal es una complicación poco frecuente y puede ser el resultado de una perforación uterina inadvertida durante su colocación $(3,5)$. Ésta debe sospecharse en pacientes con dolor agudo e imposibilidad de visualizar los hilos tras la inserción del dispositivo. Se consideran factores de riesgo de perforación uterina su inserción en mujeres con lactancia materna, en los 6 primeros meses tras el parto, la presencia de alteraciones uterinas, la inexperiencia del operador y la dificultad en su inserción $(3,5)$. La cesárea anterior no parece incrementar el riesgo de perforación uterina durante su inserción aunque se han descrito algunos casos (6). De hecho, la inserción de un DIU a través del punto de incisión inmediatamente después del parto por cesárea ha demostrado tener significativamente menores complicaciones que la inserción vaginal posparto (7).

La presencia de un DIU intraperitoneal puede ser asintomática, sin embargo, existe el riesgo de que penetre en el interior de vísceras abdominales próximas como la vejiga o el intestino, generando complicaciones más severas hasta en un $15 \%$ de los casos $(3,4)$. Una mayoría de pacientes con DIUs migrados a cavidad abdominal cursan de forma asintomática produciéndose el diagnóstico incidental ante la ausencia de visualización de los hilos en vagina, la detección de un embarazo o la realización de pruebas de imagen por otras causas (8).

Con frecuencia, el DIU se encuentra libre en la cavidad abdominal o en la pelvis, no obstante puede generar adherencias con el aparato genital, la vejiga, el intestino y el omento (9). En estos casos la migración del DIU se puede asociar preferentemente a dolor pélvico o abdominal crónico, a infertilidad y a la perforación de vísceras adyacentes $(4,10)$.

Se han descrito en la literatura múltiples casos de localización vesical del DIU siendo responsable de síntomas urinarios (hematuria, disuria), fístulas vesicouterinas y formación de cálculos $(11,12)$. Igualmente se han descrito casos de DIU migrado con afectación del colon o de intestino delgado lo que puede desembocar en fístulas, hemorragias, abscesos y casos de peritonitis $(4,13)$.

En nuestro caso, no fue posible determinar si la sintomatología dolorosa de la paciente era resultado de la migración del DIU o si tenía relación con la interrupción del embarazo.

El diagnóstico de un DIU migrado puede realizarse mediante ecografía, histeroscopia y placas de abdomen convencionales en proyección anteroposterior y lateral, sin embargo, por su disponibilidad e inocuidad la ecografía es una herramienta de gran utilidad que debe ser empleada en primer lugar (14). En nuestro caso, la visualización ectópica del DIU se realizó gracias a ecografía vaginal.

Los DIUs más comúnmente utilizados pertenecen a dos tipos: el DIU con cobre y el DIU liberador de levonorgestrel. Si bien su morfología puede 
ser similar, sus características radiológicas varían. EI DIU con cobre a la ecografía es radio opaco e hiperecogénico, mientras que el segundo contiene sulfato de bario, que si bien es radio opaco, no se visualiza tan claramente por ecografía (14). Esta distinción deberá tenerse en cuenta en caso de una migración ectópica de estos dispositivos, ya que afecta a la sensibilidad de las pruebas diagnósticas.

Otras modalidades de imagen como la tomografía computarizada (TAC) se reservan para el diagnóstico de complicaciones, como la presencia de perforación orgánica, obstrucción intestinal, abscesos, u otras $(8,14)$. La resonancia magnética (RM) no se emplea de forma habitual para la evaluación de los DIUs, no obstante pueden visualizarse de forma segura con equipos de 1,5-T y 3,0-T (15).

El tratamiento de la migración intraabdominal de un DIU consiste en la extracción quirúrgica del dispositivo por laparoscopia o laparotomía debido al potencial riesgo de lesión de órganos intraabdominales (16). La Organización Mundial de la Salud recomienda la remoción del DIU migrado tan pronto como sea posible, aún en pacientes asintomáticas e independientemente del tipo y su localización, debido a su potencial para la formación de adherencias, así como otras complicaciones (16). No obstante, algunos autores sugieren que es posible el manejo conservador en pacientes asintomáticas bajo ciertas premisas (5).

La laparoscopia es preferible a la cirugía abierta ya que comporta un procedimiento menos invasivo, sin embargo, la laparotomía puede ser necesaria cuando se detectan complicaciones intraabdominales. Un estudio realizado en 2012 evaluó 129 casos de extracción quirúrgica electiva de DIUs migrados a la cavidad abdominal. Los hallazgos sugieren, que en dicha situación, el 93\% de los procedimientos quirúrgicos se abordaron vía laparoscópica con una tasa de reconversión a laparotomía del 22,5\% influenciada por la localización común abdominopélvica del dispositivo (17). En un escaso porcentaje de casos descritos se precisó la utilización de fluoroscopia durante la cirugía para la localización del dispositivo o bien se complementó el abordaje laparoscópico mediante cistoscopia o colonoscopia para descartar lesiones en órganos adyacentes $(18,19)$.

La ubicación intramiometrial del DIU permite extraerlo mediante histeroscopia diagnóstica con las ventajas de ser un procedimiento ambulatorio que no precisa anestesia (20). Sin embargo, en caso de que haya traspasado la serosa o se encuentre embebido en estructuras peritoneales, sería preferible el abordaje abdominal (20). Ocasionalmente, la ubicación del DIU en la luz de vísceras huecas, como el colon o la vejiga, puede hacer necesaria su extracción mediante colonoscopia o cistoscopia (20).
La prevención de este tipo de complicaciones asociadas al uso del DIU como método contraceptivo incluye el conocimiento correcto de la técnica de inserción, así como de las posibles condiciones que afectan al útero (útero puerperal, retroversión, miomas). Es recomendable la comprobación ecográfica del DIU en su posición intrauterina después de la inserción del mismo, ya sea de forma inmediata o diferida. En casos que pudieran suponer dificultades técnicas como la presencia de miomas uterinos, sería posible igualmente su colocación ecoguiada para facilitar su correcta inserción y evitar perforaciones.

\section{CONCLUSIÓN}

En mujeres con el antecedente de inserción de un DIU, independientemente del tiempo transcurrido, si no existe constancia de su retiro, es recomendable realizar técnicas de imagen para demostrar su ubicación y descartar una posible migración del dispositivo a la cavidad abdominal u órganos vecinos, y programar su retiro independiente del tipo de dispositivo intrauterino o ausencia de síntomas.

\section{REFERENCIAS}

1. Sivin I, Schmidt F. Effectiveness of IUDs: a review. Contraception 1987;36(1):55-84.

2. Thonneau P, Goulard H, Goyaux N. Risk factors for intrauterine device failure: a review. Contraception 2001;64(1):33-7.

3. Harrison-Woolrych M, Ashton J, Coulter D. Uterine perforation on intrauterine device insertion: is the incidence higher than previously reported? Contraception 2003;67(1):53-6.

4. Romero S, Motta E, Juárez AA. Perforación uterina $y$ de rectosigmoides por dispositivo intrauterino, presentación de un caso con revisión de la literatura. Gac Méd Méx 2003;139(1):73-6.

5. Markovitch O, Klein Z, Gidoni Y, Holzinger M, Beyth Y. Extrauterine mislocated IUD: is surgical removal mandatory? Contraception 2002;66(2):105-8.

6. Parikh V, Gandhi AS. Safety of copper T as contraceptive after caesarean section. J Indian Med Assoc 1989;87(5):113-5.

7. O'Hanley K, Huber DH. Postpartum IUDS: keys for success. Contraception 1992;45(4):351-61.

8. Mejía J, López JE, Aldana N, Ruiz TI, Massaro M. Dispositivos intrauterinos penetrados y migrados: Hallazgos en tomografía computarizada. Rev Colom Radiol 2011;22(3):3263-71.

9. Zakin D, Stern WZ, Rosenblatt R. Complete and partial uterine perforation and embedding following insertion of intrauterine devices. II. Diagnostic methods, prevention, and management. Obstet Gynecol Surv 1981;36(8):401-17.

10. Zarhi J, Schwarze JE, Vacca F, Jarzún J, Montecinos F. Manejo laparoscópico de dispositivo intrauterino 
migrado a trompa de Falopio con hidrosálpinx secundario. Rev Chil Obstet Ginecol 2007;72(5):342-5.

11. Ceballos S, Sotelo P. Caso inusual de un dispositivo intrauterino migrado a vejiga con cistolitiasis secundaria. Rev Mex Urol 2007;67(3):184-7.

12. Zarhi J, Vacca F, Sanhueza P, Díaz J, Riffo R. Manejo laparoscópico de dispositivo intrauterino incrustado en pared vesical con litiasis vesical secundaria. Rev Chil Obstet Ginecol 2009;74(1):42-6.

13. Ozgun MT, Batukan C, Serin IS, Ozcelik B, Basbug M, Dolanbay M. Surgical management of intra-abdominal mislocated intrauterine devices. Contraception 2007;75(2):96-100.

14. Boortz HE, Margolis DJ, Ragavendra N, Patel MK, Kadell BM. Migration of intrauterine devices: radiologic findings and implications for patient care. Radiographics 2012;32(2):335-52.

15. Zieman M, Kanal E. Copper T 380A IUD and magnetic resonance imaging. Contraception 2007;75(2):93-5.
16. Mechanism of action, safety and efficacy of intrauterine devices. Report of a WHO Scientific Group. World Health Organ Tech Rep Ser 1987;753:1-91.

17. Mosley FR, Shahi N, Kurer MA. Elective surgical removal of migrated intrauterine contraceptive devices from within the peritoneal cavity: a comparison between open and laparoscopic removal. JSLS 2012;16(2):236-41.

18. Balci O, Mahmoud AS, Capar M, Colakoglu MC. Diagnosis and management of intra-abdominal, mislocated intrauterine devices. Arch Gynecol Obstet 2010;281(6):1019-22.

19. Velázquez J, Vilchis $P$, Nevarez R, Kably A. Perforación uterina y del yeyuno causada por un dispositivo intrauterino. Ginecol Obstet Mex 2006;74(8):435-8.

20. Subramanian V, Athanasias $P$, Datta $S$, Anjum $A$, Croucher $\mathrm{C}$. Surgical options for the retrieval of a migrated intrauterine contraceptive device. J Surg Case Rep 2013;2013(9). pii: rjt072. doi: 10.1093/jscr/rjt072. 